\title{
Effect of Steaming and Boiling on the Antioxidant Properties and Biogenic Amines Content in Green Bean (Phaseolus vulgaris) Varieties of Different Colours
}

\author{
Raffaella Preti, Mattia Rapa, and Giuliana Vinci \\ Laboratory of Commodity Sciences, Department of Management, Sapienza University of Rome, \\ Via del Castro Laurenziano 9, 00164 Rome, Italy \\ Correspondence should be addressed to Raffaella Preti; raffaella.preti@uniromal.it
}

Received 22 July 2016; Accepted 30 October 2016; Published 12 January 2017

Academic Editor: Elena González-Fandos

Copyright (C) 2017 Raffaella Preti et al. This is an open access article distributed under the Creative Commons Attribution License, which permits unrestricted use, distribution, and reproduction in any medium, provided the original work is properly cited.

\begin{abstract}
Effects of boiling and steaming cooking methods were studied on total polyphenols, antioxidant capacity, and biogenic amines of three green bean varieties, purple, yellow, and green. The vegetables gave good values both for antioxidant capacity and for phenolics content, with the purple variety being the richest in healthful components. Both the heat treatments affected the antioxidant properties of these vegetables, with boiling that reduced the initial antioxidant capacity till $30 \%$ in the yellow variety, having the same trend for total polyphenols, with the major decrement of $43 \%$ in the green variety. On the contrary, biogenic amines significantly increased only after boiling in green and yellow variety, while purple variety did not show any changes in biogenic amines after cooking. The steaming method showed being better cooking approach in order to preserve the antioxidant properties of green beans varieties and to maintain the biogenic amines content at the lowest level.
\end{abstract}

\section{Introduction}

In recent years, as part of a public health strategy for chronic disease prevention, five daily portions of fruits and vegetables (approximately $400 \mathrm{~g} /$ day) have been recommended [1]. In fact, literature shows that plant food consumption is related to mortality reduction, including mortality from cardiovascular diseases, type 2 diabetes, and cancer [2]. This may be due in part to the high amounts of beneficial components present in vegetables such as dietary fiber, folate, antioxidants, vitamins, polyphenols, and potassium [3]. Phytochemicals, in particular, are recognized as being responsible for these protective effects. They are secondary plant metabolites responsible for plant food colour, smell, flavor, and bitterness and consist of a wide variety of different molecules, all important for diseases prevention by impacting the production and the action of free radicals.

Biogenic amines (BAs) are natural contaminants originated from enzymatic decarboxylation of the corresponding amino acid. As the microbial spoilage of food may be accompanied by the increased production of decarboxylases, the presence of BAs might serve as a useful indicator of food spoilage [4]. They are ubiquitous in all food, but in particular in fermented food, and can exert negative impacts on human health, especially tyramine and histamine [5].

In vegetables polyamines are particularly present, where they play different roles in the cellular metabolism. Putrescine (PUT), spermine (SPM), and spermidine (SPD) are considered to be bioregulators of numerous cell functions, being involved in the process of cell growth, division, and differentiation. These BAs are also involved in tissue repair and in intracellular signaling.

On the other hand, polyamines, although not exerting a direct toxic effect, can potentiate the toxic effects of tyramine and histamine by competing for the detoxifying enzymes and act as precursors of carcinogenic nitrosamines.

Furthermore, some authors [6] have reported that a polyamine deprivation regime can have beneficial effects in reducing tumor growth.

Moreover, the beneficial effects of the diamine agmatine (AGM) for human health, in its various functions from neurotransmitter or neuromodulator to stimulator of 
insulin release and tumor suppressor agent are well known [7].

While fruit consumption occurs most often in its fresh form, vegetables are usually consumed after cooking, which can be performed in different ways, according to culinary traditions or personal tastes.

Food processing not only improves flavor, digestibility, and palatability of foods but also increases food safety by microorganism destruction and by antinutritional factors inactivation.

On the other hand, biological, chemical, and physical properties of vegetables are modified during the thermal process; these modifications include changes in texture or turgor, smell, and colour but the most important changes, in the nutritional point of view, are the influence on the concentration and bioavailability of bioactive compounds in vegetables [8].

However, both positive and negative effects on polyphenols content and antioxidant capacity have been reported in recent literature. In fact, the cooking process can cause the thermal degradation of phytochemicals, but also it can increase their total content by enhancing their availability for extraction, inactivating the polyphenol oxidase, or releasing fiber-bound polyphenols into free polyphenols [8]. The final result depends upon differences in process conditions and morphological and nutritional characteristics of vegetable species [9-12].

Regarding the fate of BAs after the cooking process, few and contradictory studies have been reported. Some authors concluded that these compounds are heat stable compounds and their level is not significantly reduced by high temperature treatment [13]. According to other authors, cooking processes and heat treatments can influence polyamine contents $[14,15]$.

For example, Shalaby reported that although biogenic amines in some type of legumes can be eliminated through boiling, boiling is not effective in eliminating biogenic amines in sprouted legumes. However, biogenic amines are reported in boiled and grilled eggplant as heat stable compounds [16] and cooking or prolonged exposure to heat will not eliminate the toxin $[17,18]$.

Overall, in meat products losses of both SPD and SPM varied in the range of $30-50 \%$ of their initial content prior to cooking [19-23].

Therefore, the effectiveness of biogenic amines reduction via heating treatment requires experimentation on each produce crop type via different cooking methods.

Green beans are the unripe fruit and protective pods of various cultivars of the common bean (Phaseolus vulgaris), belonging to the legume family Fabaceae. Green beans are highly appreciated all over the world for their fleshiness, flavor, and sweetness. From a nutritional point of view, they are good source of vitamins, fibers, and antioxidant compounds [24]; therefore, it is important to understand how thermal processing affects the nutritional quality of these vegetables.

There are several green bean varieties available in the market; they differentiate for textures or colours or flavors.
In recent literature, there are some studies investigating the presence of antioxidant compounds in green beans as raw vegetables $[24,25]$ during cooking process $[26,27]$ and in canned green beans [28]. To our knowledge, no study has been reported on the presence of biogenic amines in green beans and on the difference of total phenols content and antioxidant capacity among green beans cultivars, which otherwise could be an interesting aspect to explore, since different colours in vegetables are reported to be associated with dissimilar antioxidants profiles and levels [29]. Interesting, also, is the knowledge of the evolution of all these parameters during the cooking processes in relation to a comparative approach of different cultivars and cooking methods.

The present study is aimed at evaluating the cooking induced changes in green beans on total polyphenols and biogenic amines content and on their antioxidant capacity, before and after two most common cooking ways, steaming and boiling. The vegetables studied belonged to three different cultivars, which mainly differed for pod colour: (a) Cv Purple Queen, heirloom pole bean with beautiful purple pods, purple-veined leaves, and violet flowers: the large purple pods are easy to see, making harvesting easier; (b) Cv Brittle Wax, producing beautiful, uniformly slender filet-style beans, but with yellow colour and great flavor; (c) $\mathrm{Cv}$ Allure, fine green filet bean that produces slender, stringless pods. The results have been evaluated in relation to different cultivars of origin and to different cooking methods.

\section{Materials and Methods}

2.1. Sampling. Green beans were purchased from local markets in Rome, Italy, and used as research material.

The vegetables ( $2 \mathrm{~kg}$ for each variety) were randomly sampled from the shelf.

Vegetables were washed with tap water after removing manually inedible parts with a sharp knife, dried on paper towel, and cut into almost equal small pieces or slices, mixed well, and $900 \mathrm{~g}$ was taken and divided into three portions (300 $\mathrm{g}$ for each application). One portion was retained raw; others were cooked in two different methods in triplicate, as given below. Cooking conditions were determined, with a preliminary experiment for each green bean variety.

Boiling: vegetable ( $100 \mathrm{~g}$ ) was added to $200 \mathrm{ml}$ of water that had just reached the boil in a stainless steel pan and cooked for $10 \mathrm{~min}$. The samples were drained off and cooled rapidly on plenty of ice.

Steaming: vegetable was placed on tray in a steam cooker covered with lid and steamed over boiling water for $15 \mathrm{~min}$ under atmospheric pressure. The samples rapidly cooled on ice.

\subsection{Analytical Methods}

2.2.1. Chemicals. Methanol, acetonitrile (HPLC grade), perchloric acid, Folin-Ciocalteu reagent, 2,2-azino-bis (3-ethylbenzothiazoline-6-sulfonic acid) diammonium salt (ABTS), 2,2-diphenyl-1-picrylhydrazyl (DPPH), potassium persulfate $(+/-)$, gallic acid (GA), and sodium carbonate were from 
Sigma Chemical Co. (St. Louis, MO, USA). Distilled water was purified using a Milli-Q system (Millipore, Bedford, MA, USA).

The eleven biogenic amines studied were ethylamine (ETA), methylamine (MEA), histamine (HIS), serotonin (SER), spermine (SPM), spermidine (SPD), agmatine (AGM), putrescine (PUT), $\beta$-phenylethylamine ( $\beta$-PEA), cadaverine (CAD), and tyramine (TYM) all of which were supplied by Supelco, Bellefonte, PA, USA, as well as the derivatizing agent dansyl chloride and the internal standard 1,7-diaminoheptane (IS).

2.3. Sample Extraction: Antioxidant Capacity and Total Polyphenols. Sample extractions for the antioxidant capacity and the phenols content were prepared from $10 \mathrm{~g}$ of green beans, in $50 \mathrm{ml}$ of methanol (Labscan, Ireland). Samples were homogenized in an Ultra-Turrax for $3 \mathrm{~min}$ and then centrifuged at $3000 \mathrm{rpm}$ for $5 \mathrm{~min}$.

2.3.1. Determination of Antioxidant Capacity. The DPPH free radical scavenging activity of the sample extract was evaluated by measuring the decrease in absorbance at $515 \mathrm{~nm}$ as previously reported [30]. The absorbance was measured against methanol using a Lenway 6705 UV-Vis spectrophotometer with $1 \mathrm{~cm}$ path length cuvettes.

Antioxidant capacity was determined also by the ABTS assay conducted by the method by Thaipong et al. [31]. The disappearance of $\mathrm{ABTS}^{*}{ }^{*}$ was determined by measuring the decrease in absorbance at $734 \mathrm{~nm}$.

Results were calculated using the inhibition rate $(I)$ of the radical cation for both the assays, according to the following equation:

$$
I \%=\frac{A 0-A f}{A 0} \cdot 100
$$

$A 0$ is radical cation initial absorbance; $A f$ is absorbance after sample extract adding.

2.3.2. Determination of Total Phenolics Content. Total phenolics content was determined using the Folin-Ciocalteu method according to Singleton et al. [32]. Total phenolics content was expressed as milligrams GA equivalent (GAE) per $100 \mathrm{~g} \mathrm{FW}$.

2.4. Biogenic Amines. HPLC chromatographic separation of biogenic amines was developed in a system consisting in a LC-10 ATVP binary HPLC pump with RF-10AXL fluorescence detector (Shimadzu, Kyoto, Japan). The injector was fitted with a $20 \mu \mathrm{l}$ loop. The chromatographic data were collected and processed using Class-VP software (Shimadzu). The analytical method was rapid and sensitive as described in a previous work [33], which involved a Kinetex C18 core-shell particle column $(100 \mathrm{~mm} \times 4.6 \mathrm{~mm}, 2.6$ um particle size $)$. Fluorescence detection was set at $320 \mathrm{~nm}$ for excitation and $523 \mathrm{~nm}$ for emission. Identification of the biogenic amines was based on their retention times. Accuracy (recovery $>$ $94 \%)$ and precision (RSD < 4\%) were evaluated in triplicate using samples spiked at two concentration levels of biogenic amines. Quantitation was performed using the internal standard calibration method using linear regression analysis $(r \geq$ 0.999).

Biogenic amines from green bean samples were extracted according to a previously optimized method [34]. Briefly, $5 \mathrm{~g}$ of green beans, previously added with IS $(0.5 \mathrm{~mL})$, was extracted with $15 \mathrm{~mL}$ of $\mathrm{HClO}_{4} 0.6 \mathrm{M}$, homogenized for 3 minutes, and centrifuged at $4000 \mathrm{rpm}$ for $10 \mathrm{~min}$. Supernatant was filtered through a $0.20 \mu \mathrm{m}$ membrane Millipore filter and sediment was added with $8 \mathrm{~mL}$ of $\mathrm{HClO}_{4} 0.6 \mathrm{M}$, mixed, and centrifuged again for $3 \mathrm{~min}$. The second extract was then filtered and added to the first. The final volume was adjusted to $25 \mathrm{~mL}$ with $\mathrm{HClO}_{4} 0.6 \mathrm{M}$. An aliquot of $1 \mathrm{~mL}$ of the final extract was then derivatized by adding $200 \mu \mathrm{L}$ of $\mathrm{NaOH} 2 \mathrm{M}, 300 \mu \mathrm{L}$ of saturated $\mathrm{NaHCO}_{3}$ solution, and $2 \mathrm{~mL}$ of dansyl chloride solution (10 $\mathrm{mg} / \mathrm{mL}$ in acetone). After shaking, samples were left in the dark at $45^{\circ} \mathrm{C}$ for $60 \mathrm{~min}$. The final volume was adjusted to $5 \mathrm{~mL}$ by adding acetonitrile. The dansylated extract was filtered using $0.22 \mu \mathrm{m}$ (Polypro Acrodisc, Pall Gelman Laboratory, USA) and injected into the chromatograph.

2.5. Statistical Analysis. One-way analysis of variance (ANOVA) was performed for each green bean to obtain a statistical assessment of the evolution of the physiochemical parameters during storage. Means were separated by Fisher's least significant difference (LSD) test at $p \leq 0.05$ significance, using the Statistical Analysis System (SAS Ver. 9.0). Correlation analysis was performed and the Pearson correlation coefficient was calculated.

\section{Results and Discussion}

In all the assayed green beans varieties, the fresh weight after steaming, in comparison to the raw one, showed a decrease due to a water loss of the vegetable tissue. On the other hand, the boiling process induced a water intake and, therefore, an increase of weight in all samples. Therefore, to allow the comparison among varieties and cooking methods, all the results are expressed in terms of fresh weight $(\mathrm{FW})$.

3.1. Antioxidant Capacity and Total Polyphenols. The antioxidant activity was measured by two different assays as has been recommended until antioxidant activity in foods is fully understood. The results of the two assays based on the scavenging capacity of two free radicals (ABTS* and DPPH) by the samples methanol extract are shown in Table 1 and plotted in Figure 1. The present results showed a good overall correlation between the two assays $(r=0.95)$.

Both the assays gave similar results in the raw vegetables antioxidant ranking, with the purple variety having the highest scavenging activity followed by the green and the yellow variety.

After the cooking methods all the green beans varieties resulted in a significant decrement $(p<0.05)$ of their antioxidant capacity, except for the purple type in the DPPH assay, whose value did not show any significant change after cooking. 
TABLE 1: Effect of different cooking methods on total phenolic content and antioxidant capacity of three green beans varieties.

\begin{tabular}{|c|c|c|c|c|}
\hline Variety & Cooking method & $\mathrm{DPPH}(I \%)$ & Folin (mgGAE/100 g FW) & $\operatorname{ABTS}(I \%)$ \\
\hline \multirow{3}{*}{ Purple(Cv Purple Queen) } & Raw & $78.40 \pm 1.44^{\mathrm{a}}$ & $23.20 \pm 0.12^{\mathrm{a}}$ & $96.00 \pm 0.58^{\mathrm{a}}$ \\
\hline & Steaming & $75.55 \pm 1.45^{\mathrm{a}}$ & $21.68 \pm 0.17^{\mathrm{b}}$ & $90.80 \pm 1.43^{\mathrm{b}}$ \\
\hline & Boiling & $68.97 \pm 1.46^{\mathrm{b}}$ & $15.03 \pm 0.09^{c}$ & $83.10 \pm 0.14^{\mathrm{c}}$ \\
\hline \multirow{3}{*}{ Green (Cv Allure) } & Raw & $66.70 \pm 1.55^{\mathrm{a}}$ & $11.87 \pm 0.15^{\mathrm{a}}$ & $53.51 \pm 2.26^{\mathrm{a}}$ \\
\hline & Steaming & $52.60 \pm 1.50^{\mathrm{b}}$ & $8.30 \pm 0.11^{b}$ & $47.80 \pm 1.03^{\mathrm{b}}$ \\
\hline & Boiling & $47.60 \pm 1.56^{\mathrm{c}}$ & $6.78 \pm 0.16^{\mathrm{c}}$ & $38.60 \pm 0.58^{c}$ \\
\hline \multirow{3}{*}{ Yellow (Cv Brittle Wax) } & Raw & $54.20 \pm 1.17^{\mathrm{a}}$ & $7.81 \pm 0.15^{\mathrm{a}}$ & $45.70 \pm 1.84^{\mathrm{a}}$ \\
\hline & Steaming & $46.70 \pm 1.38^{\mathrm{b}}$ & $6.29 \pm 0.18^{\mathrm{b}}$ & $39.40 \pm 1.24^{\mathrm{b}}$ \\
\hline & Boiling & $38.60 \pm 1.27^{\mathcal{C}}$ & $5.25 \pm 0.03^{\mathrm{c}}$ & $31.05 \pm 1.32^{\mathrm{c}}$ \\
\hline
\end{tabular}

Data are expressed as means \pm standard deviation of triplicate experiments. Mean values in a column with different letters are significantly different $(p<0.05)$ with the LSD test for each green bean variety.

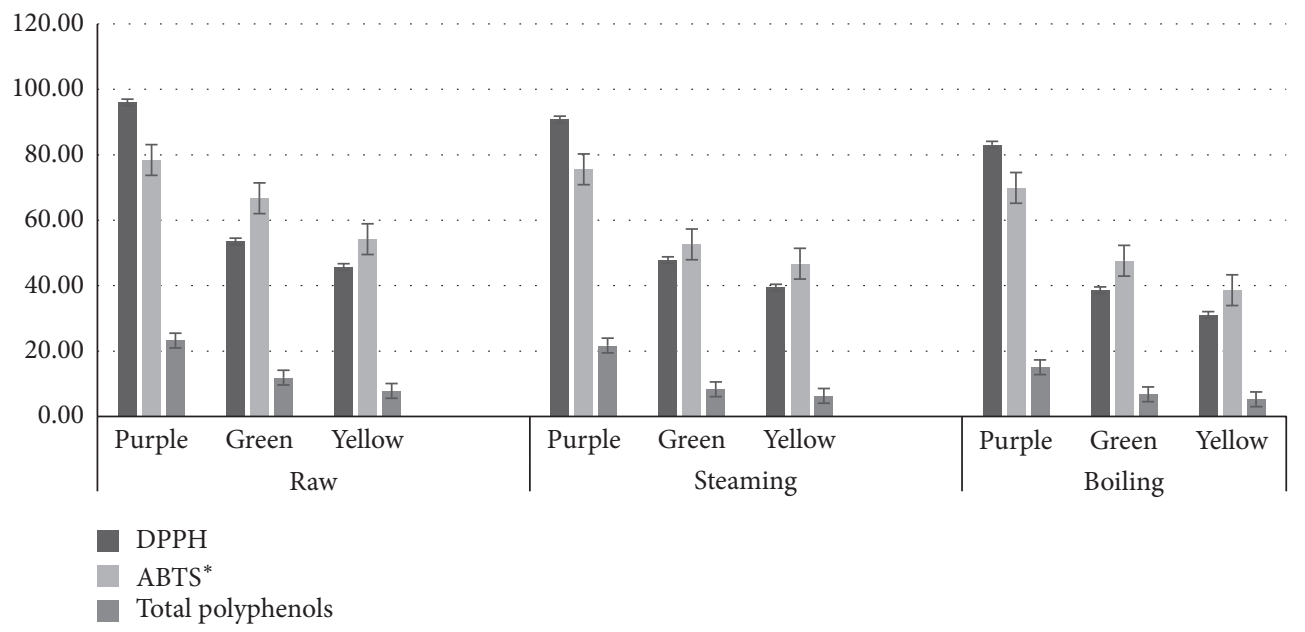

FIGURE 1: Effect of boiling and steaming treatment on the antioxidant activity (I\%) and total polyphenols (mg/100 g FW) on three green beans varieties.

The cooking method that affected most the antioxidant capacity was boiling, with a decrease of the DPPH assay in the yellow variety of $29 \%$ value and of $32 \%$ of the ABTS* assay value in comparison to the raw sample. The decrement in the ABTS* assay value caused by the steaming method ranged from $5.4 \%$ for the violet type to $14 \%$ for the white type, the same as that in the DPPH assay for this type of bean. Same trends have been described in the previous article by Baardseth et al. [24] for boiled green beans where the DPPH assay value loss reached $40 \%$, and in the work by Jiratanan and Liut [28] the total antioxidant activity of boiled green beans for $10 \mathrm{~min}$ at constant temperature showed a $9 \%$ decrease in total antioxidant activity as compared to the raw control. These findings are in contrast to those reported by of Jiménez-Monreal et al. [35] and Ismail et al. [36] that detected no decrement in ABTS radical scavenging, and those by Turkmen et al. [27] reported $162 \%$ recovery in DPPH in boiled green beans and $185 \%$ in steamed green beans.

Polyphenols are a large class of plant secondary metabolites important for the quality of plant based foods: they are responsible for the colour foods and are also involved in flavor properties [37]. As expected, from their function of natural pigments, the total polyphenol content in raw green beans ranged from 78.1 in the yellow variety to 232 in the purple variety $\mathrm{mg}$ GAE/100 $\mathrm{g}$ FW.

The concentrations of total polyphenol contents of the cooked vegetables are shown in Table 1 with comparison of raw vegetables. Cooking style affected total polyphenol content of samples. Both steaming and boiling methods of cooking significantly affected $(p<0.05)$ total polyphenol content on the three types of tested green beans, but the boiling method resulted in the highest loss of total polyphenolic content with respect to the raw vegetable: $42.9 \%$ in green variety, followed by the purple variety with $35.2 \%$ and the yellow variety with $32.8 \%$. The steaming method seemed to preserve better the polyphenols content with a $6.5 \%$ decrease in purple, $19.4 \%$ in yellow, and $30.0 \%$ in green variety. The results indicated that polyphenolic compounds were very sensitive to heat treatment.

The data on total polyphenols were in good agreement with both the radical scavenging assays for antioxidant capacity assessment $\left(r=0.97\right.$ with ABTS $^{*}$ and $r=0.95$ with $\mathrm{DPPH}$.

The high correlation among antioxidant capacity and phenolic compounds in fruit and vegetables has been previously reported with a similar magnitude [38, 39]; these 


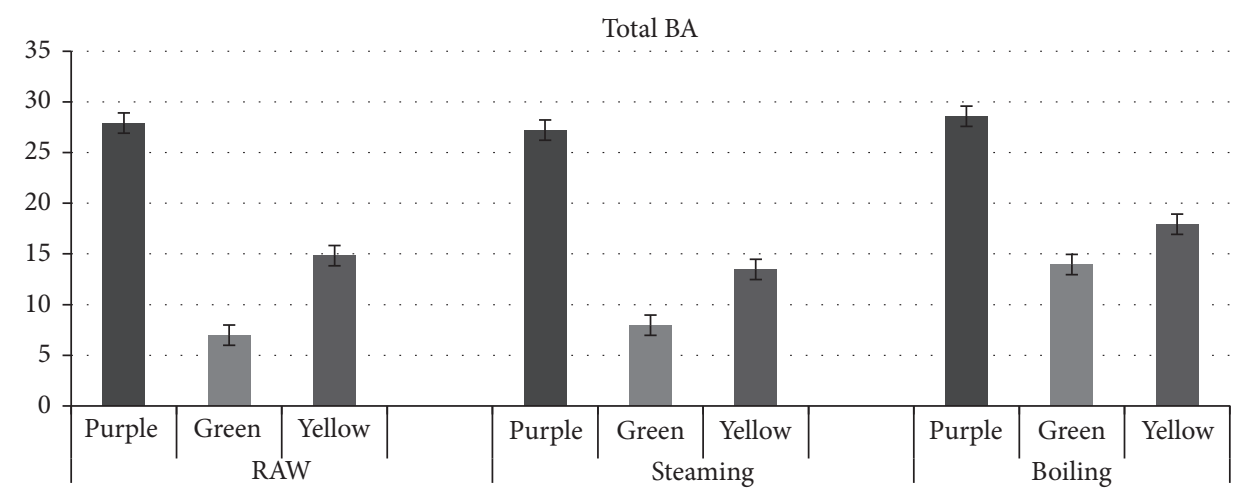

FIGURE 2: Effect on the total level of biogenic amines (mg/100 $\mathrm{g} \mathrm{FW)} \mathrm{of} \mathrm{steaming} \mathrm{and} \mathrm{boiling} \mathrm{treatment} \mathrm{of} \mathrm{three} \mathrm{varieties} \mathrm{of} \mathrm{green} \mathrm{beans.}$

findings suggest that phenolic compounds are a major contributor to antioxidant capacity in these foods. For this reason, we have assumed that the factors involved in the polyphenols loss were the same causing the antioxidant activity decrement in samples.

The loss can be attributed to the water soluble compounds leaching into the cooking water as well as the breakdown of these compounds during cooking [40]. This process can be increased by the fact that prior to cooking green beans are cut to remove the inedible parts; cutting operations are in fact reported to reduce polyphenols due to oxygen exposure and to the polyphenol oxidase activation [41, 42].

These discrepancies in the results reported in literature can be explained by differences in the extraction and cooking methods. Podsedek et al. [43] in fact reported the phenolic losses proportional to boiling time and to the amount of water. The great variability related to the different varieties of vegetables studied has been deeply summarized in the review by Palermo et al. [8]. As an example of this extreme variability, which prevents arriving to any generalization, we can consider the work by Faller and Fialho [44] where organic vegetables showed a higher sensitivity to the heating process than conventional counterparts.

3.2. Biogenic Amines. The biogenic amines in green beans cooked by different methods are shown in Table 2. In this study, the highest total mean biogenic amine content in raw green beans was determined in the purple variety $(27.92 \mathrm{mg} / 100 \mathrm{~g} \mathrm{FW})$ followed by the green variety $(14.83 \mathrm{mg} / 100 \mathrm{~g} \mathrm{FW})$ and white variety $(6.99 \mathrm{mg} / 100 \mathrm{~g}$ FW) (Figure 2). Ethylamine, cadaverine, histamine, serotonin, and tyramine were not detected in any sample. Bphenylethylamine was detected only in boiled vegetables.

The green and the yellow varieties showed a significant increment $(p<0.05)$ of biogenic amines after boiling. In the yellow variety, MEA, SPD, and SPM were almost triplicated in comparison to the raw sample, while PUT and AGM increased by $24 \%$ and $44 \%$, respectively. In the green variety, resulting MEA doubled in comparison to the raw sample and AGM had an increment of $31 \%$. The only biogenic amine that showed a significant decrement during the cooking process was SPM in the green variety after steaming.
The purple variety behavior during both the cooking methods was quite different. The only two biogenic amines that had a change after boiling were BPEA and SPM, with a $41.5 \%$ increment.

There are few works in literature dealing with the presence of biogenic amines in vegetables [45-48] and no one on the presence of these compounds in green beans. Furthermore, to our knowledge there is only a study on the evolution of biogenic amines in vegetable during cooking [16] that focuses only on the sum of PUT and SPD in three eggplant genotypes before and after boiling and grilling, showing a significant increment of $55 \%$ after boiling only in one of the three genotypes.

Due to the scarcity of previous studies on the cooking induced changes in biogenic amines levels in vegetables only some hypothesis can be postulated on the results on green beans. The general trend on an increment of all the biogenic amines after boiling can originate (i) from the possible inactivation of the amine oxidase enzymes due to high temperature; (ii) from an enhanced availability for extraction, to a more efficient release of biogenic amines from intracellular proteins and altered cell structures [8]; (iii) from the degradation of other compounds, including precursor amino acids.

The highest content in raw purple sample of BAs and of antioxidant compounds, together with a firmer structure at the end of the heat treatment, in comparison to the other varieties, can be therefore for further investigations to understand the different behavior in this type of green beans and to deepen the causes for the general increment of BA in this vegetable. Furthermore, the results confirm that each variety of each food product needs to be subject of experimentation, highlighting the great variability of different genotypes.

\section{Conclusions}

The present study aimed to evaluate the changes of antioxidant properties and biogenic amines content of three different varieties of green beans, chosen for presenting different colours in the raw form, after boiling and steaming treatments. The results show a good antioxidant content in all 


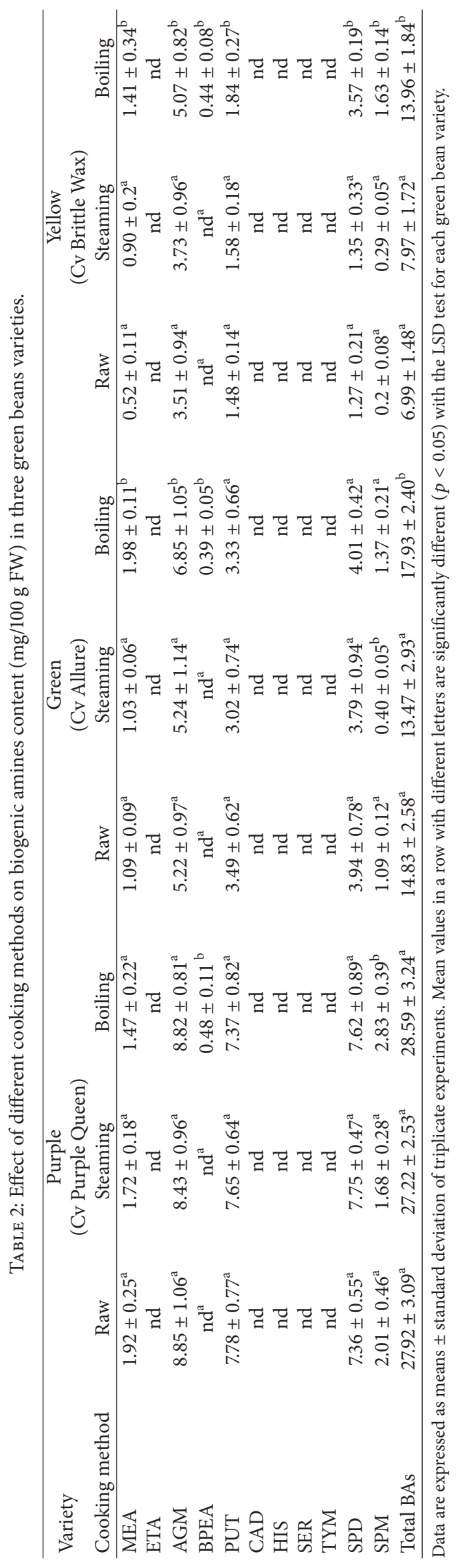


the varieties considered, but, as expected, with a highest concentration of healthy compounds in the purple variety. Both the cooking methods affected the antioxidant properties, with steaming being the method that preserved better the initial content. Furthermore, steaming, unlike boiling, did not result in an increment of the biogenic amines studied in green beans, being therefore the preferable heat treatment.

Further studies need to be conducted on different vegetables matrices, taking into account all the potential sources of variability, such as genotype, cooking, and extraction procedures, in order to have a general knowledge on the preservation of nutritional quality of food.

\section{Additional Points}

Practical Application. Green beans are a popular vegetable, consumed for their good taste and because they are good source of antioxidants. The present article aims to evaluate the evolution of antioxidants and biogenic amines during domestic cooking, giving practical indications on the best cooking method for the green beans quality preservation.

\section{Competing Interests}

The authors declared that they have no conflict of interests.

\section{References}

[1] World Health Organization (WHO), "Diet, nutrition and the prevention of chronic diseases," WHO Technical Report Series 916, World Health Organization (WHO), Geneva, Switzerland, 2015.

[2] E. J. Nicklett, R. D. Semba, E. M. Simonsick et al., "Diet quality and social support: factors associated with serum carotenoid concentrations among older disabled women (The Women's Health and Aging Study)," Journal of Nutrition, Health and Aging, vol. 16, no. 6, pp. 511-518, 2012.

[3] Y. Aguilera, M. A. Martin-Cabrejas, and E. González de Mejia, "Phenolic compounds in fruits and beverages consumed as part of the mediterranean diet: their role in prevention of chronic diseases," Phytochemistry Reviews, vol. 15, pp. 405-423, 2016.

[4] M. H. Silla Santos, "Biogenic amines: their importance in foods," International Journal of Food Microbiology, vol. 29, no. 2-3, pp. 213-231, 1996.

[5] R. Preti, S. Vieri, and G. Vinci, "Biogenic amine profiles and antioxidant properties of Italian red wines from different price categories," Journal of Food Composition and Analysis, vol. 46, pp. 7-14, 2016.

[6] K. A. Eliassen, R. Reistad, U. Risoen, and H. F. Ronning, "Dietary polyamines," Food Chemistry, vol. 78, no. 3, pp. 273280, 2002.

[7] F. Galgano, M. Caruso, F. Favati, and P. Romano, "Focused review: agmatine in fermented foods," Frontiers in Microbiology, vol. 3, pp. 199-208, 2003.

[8] M. Palermo, N. Pellegrini, and V. Fogliano, "The effect of cooking on the phytochemical content of vegetables," Journal of the Science of Food and Agriculture, vol. 94, no. 6, pp. 1057-1070, 2014.
[9] M. C. Nicoli, M. Anese, and M. Parpinel, "Influence of processing on the antioxidant properties of fruit and vegetables," Trends in Food Science and Technology, vol. 10, no. 3, pp. 94-100, 1999.

[10] S. K. Lee and A. A. Kader, "Preharvest and postharvest factors influencing vitamin C content of horticultural crops," Postharvest Biology and Technology, vol. 20, no. 3, pp. 207-220, 2000.

[11] C. Miglio, E. Chiavaro, A. Visconti, V. Fogliano, and N. Pellegrini, "Effects of different cooking methods on nutritional and physicochemical characteristics of selected vegetables," Journal of Agricultural and Food Chemistry, vol. 56, no. 1, pp. 139-147, 2008.

[12] M. Şengül, H. Yildiz, and A. Kavaz, "The effect of cooking on total polyphenolic content and antioxidant activity of selected vegetables," International Journal of Food Properties, vol. 17, no. 3, pp. 481-490, 2014.

[13] A. Naila, S. Flint, G. Fletcher, P. Bremer, and G. Meerdink, "Control of biogenic amines in food-existing and emerging approaches," Journal of Food Science, vol. 75, no. 7, pp. R139R150, 2010.

[14] M. P. G. Cirilo, A. F. S. Coelho, C. M. Araújo, F. R. B. Gonçalves, F. D. Nogueira, and M. B. A. Glória, "Profile and levels of bioactive amines in green and roasted coffee," Food Chemistry, vol. 82, no. 3, pp. 397-402, 2003.

[15] A. R. Shalaby, "Changes in biogenic amines in mature and germinating legume seeds and their behavior during cooking," Food, vol. 44, no. 1, pp. 23-27, 2000.

[16] R. Lo Scalzo, M. Fibiani, G. Francese et al., "Cooking influence on physico-chemical fruit characteristics of eggplant (Solanum melongena L.)," Food Chemistry, vol. 194, pp. 835-842, 2016.

[17] P. G. Duflos, "Histamine risk in fishery products," Bulletin de l'Academie Veterinaire de France, vol. 162, no. 3, pp. 241-246, 2009.

[18] V. E. Gonzaga, A. G. Lescano, A. A. Huamán, G. SalmónMulanovich, and D. L. Blazes, "Histamine levels in fish from markets in Lima, Peru," Journal of Food Protection, vol. 72, no. 5, pp. 1112-1115, 2009.

[19] E. Dadáková, T. Pelikánová, and P. Kalač, “Concentration of biologically active polyamines in meat and liver of sheep and lambs after slaughter and their changes in mutton during storage and cooking," Meat Science, vol. 87, no. 2, pp. 119-124, 2011.

[20] E. Dadáková, T. Pelikánová, and P. Kalač, “Concentration of biologically active polyamines in rabbit meat, liver and kidney after slaughter and their changes during meat storage and cooking," Meat Science, vol. 90, no. 3, pp. 796-800, 2012.

[21] E. Dadáková, T. Pelikánová, and P. Kalač, "Contents of biologically active polyamines in duck meat and giblets after slaughter and their changes during meat storage and cooking," Food Research International, vol. 48, no. 1, pp. 28-33, 2012.

[22] M. Kozová, P. Kalač, and T. Pelikánová, "Biologically active polyamines in pig kidneys and spleen: content after slaughter and changes during cold storage and cooking," Meat Science, vol. 79, no. 2, pp. 326-331, 2008.

[23] L. Li, P. Wang, X. Xu, and G. Zhou, "Influence of various cooking methods on the concentrations of volatile $\mathrm{N}$-nitrosamines and bbiogenic amines in dry-cured sausages," Journal of Food Science, vol. 77, no. 5, 2012.

[24] P. Baardseth, F. Bjerke, B. K. Martinsen, and G. Skrede, "Vitamin $\mathrm{C}$, total phenolics and antioxidative activity in tip-cut green beans (Phaseolus vulgaris) and swede rods (Brassica napus var. napobrassica) processed by methods used in catering," Journal 
of the Science of Food and Agriculture, vol. 90, no. 7, pp. 12451255, 2010.

[25] M. Dolinsky, C. Agostinho, D. Ribeiro et al., "Effect of different cooking methods on the polyphenol concentration and antioxidant capacity of selected vegetables," Journal of Culinary Science \& Technology, vol. 14, no. 1, pp. 1-12, 2016.

[26] C. Iborra-Bernad, P. García-Segovia, and J. Martínez-Monzó, "Physico-chemical and structural characteristics of vegetables cooked under sous-vide, cook-vide, and conventional boiling," Journal of Food Science, vol. 80, no. 8, pp. E1725-E1734, 2015.

[27] N. Turkmen, F. Sari, and Y. S. Velioglu, “The effect of cooking methods on total phenolics and antioxidant activity of selected green vegetables," Food Chemistry, vol. 93, no. 4, pp. 713-718, 2005.

[28] T. Jiratanan and R. H. Liut, "Antioxidant activity of processed table beets (Beta vulgaris var, conditiva) and green beans (Phaseolus vulgaris L.)," Journal of Agricultural and Food Chemistry, vol. 52, no. 9, pp. 2659-2670, 2004.

[29] T. Shoji, "Polyphenols as natural food pigments: changes during food processing," American Journal of Food Technology, vol. 2, no. 7, pp. 570-581, 2007.

[30] R. Preti and G. Vinci, "Nutritional and sensory evaluation of ready-to-eat salads during shelf life," Agro FOOD Industry $\mathrm{Hi}$ Tech, vol. 27, no. 1, 2016.

[31] K. Thaipong, U. Boonprakob, K. Crosby, L. Cisneros-Zevallos, and D. Hawkins Byrne, "Comparison of ABTS, DPPH, FRAP, and ORAC assays for estimating antioxidant activity from guava fruit extracts," Journal of Food Composition and Analysis, vol. 19, no. 6-7, pp. 669-675, 2006.

[32] V. L. Singleton, R. Orthofer, and R. M. Lamuela-Raventos, "Total phenolic contents and antioxidant activities of different extracts and fractions from the aerial parts of Artemisia biennis," Methods in Enzymology, vol. 299, pp. 152-178, 1999.

[33] R. Preti, M. L. Antonelli, R. Bernacchia, and G. Vinci, "Fast determination of biogenic amines in beverages by a core-shell particle column," Food Chemistry, vol. 187, pp. 555-562, 2015.

[34] E. Chiacchierini, D. Restuccia, and G. Vinci, "Evaluation of two different extraction methods for chromatographic determination of bioactive amines in tomato products," Talanta, vol. 69, no. 3, pp. 548-555, 2006.

[35] A. M. Jiménez-Monreal, L. García-Diz, M. Martínez-Tomé, M. Mariscal, and M. A. Murcia, "Influence of cooking methods on antioxidant activity of vegetables," Journal of Food Science, vol. 74, no. 3, pp. H97-H103, 2009.

[36] A. Ismail, Z. M. Marjan, and C. W. Foong, "Total antioxidant activity and phenolic content in selected vegetables," Food Chemistry, vol. 87, no. 4, pp. 581-586, 2004.

[37] V. Cheynier, "Phenolic compounds: from plants to foods," Phytochemistry Reviews, vol. 11, no. 2, pp. 153-177, 2012.

[38] D.-O. Kim, O. K. Chun, Y. J. Kim, H.-Y. Moon, and C. Y. Lee, "Quantification of polyphenolics and their antioxidant capacity in fresh plums," Journal of Agricultural and Food Chemistry, vol. 51, no. 22, pp. 6509-6515, 2003.

[39] A. Floegel, D.-O. Kim, S.-J. Chung, S. I. Koo, and O. K. Chun, "Comparison of ABTS/DPPH assays to measure antioxidant capacity in popular antioxidant-rich US foods," Journal of Food Composition \& Analysis, vol. 24, no. 7, pp. 1043-1048, 2011.

[40] A. Crozier, M. E. J. Lean, M. S. McDonald, and C. Black, "Quantitative analysis of the flavonoid content of commercial tomatoes, onions, lettuce, and celery," Journal of Agricultural and Food Chemistry, vol. 45, no. 3, pp. 590-595, 1997.
[41] P. Stratil, B. Klejdus, and V. Kubáň, “Determination of total content of phenolic compounds and their antioxidant activity in vegetables-evaluation of spectrophotometric methods," Journal of Agricultural and Food Chemistry, vol. 54, no. 3, pp. 607616, 2006.

[42] U. Pérez-López, C. Pinzino, M. F. Quartacci, A. Ranieri, and C. Sgherri, "Phenolic composition and related antioxidant properties in differently colored lettuces: a study by electron paramagnetic resonance (EPR) kinetics," Journal of Agricultural and Food Chemistry, vol. 62, no. 49, pp. 12001-12007, 2014.

[43] A. Podsedek, D. Sosnowska, M. Redzynia, and M. Koziołkiewicz, "Effect of domestic cooking on the red cabbage hydrophilic antioxidants," International Journal of Food Science and Technology, vol. 43, no. 10, pp. 1770-1777, 2008.

[44] A. L. K. Faller and E. Fialho, "The antioxidant capacity and polyphenol content of organic and conventional retail vegetables after domestic cooking," Food Research International, vol. 42, no. 1, pp. 210-215, 2009.

[45] P. Kalač, S. Švecová, and T. Pelikánová, "Levels of biogenic amines in typical vegetable products," Food Chemistry, vol. 77, no. 3, pp. 349-351, 2002.

[46] S. Moret, D. Smela, T. Populin, and L. S. Conte, "A survey on free biogenic amine content of fresh and preserved vegetables," Food Chemistry, vol. 89, no. 3, pp. 355-361, 2005.

[47] S. M. Vieira, K. H. Theodoro, and M. B. A. Glória, "Profile and levels of bioactive amines in orange juice and orange soft drink," Food Chemistry, vol. 100, no. 3, pp. 895-903, 2007.

[48] R. Preti, R. Bernacchia, and G. Vinci, "Chemometric evaluation of biogenic amines in commercial fruit juices," European Food Research and Technology, vol. 242, no. 12, pp. 2031-2039, 2016. 



Submit your manuscripts at

https://www.hindawi.com
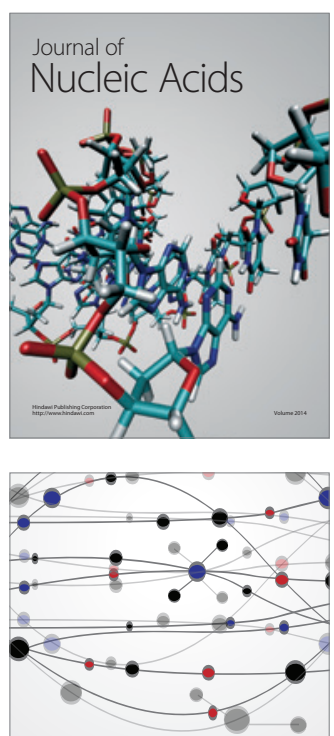

The Scientific World Journal
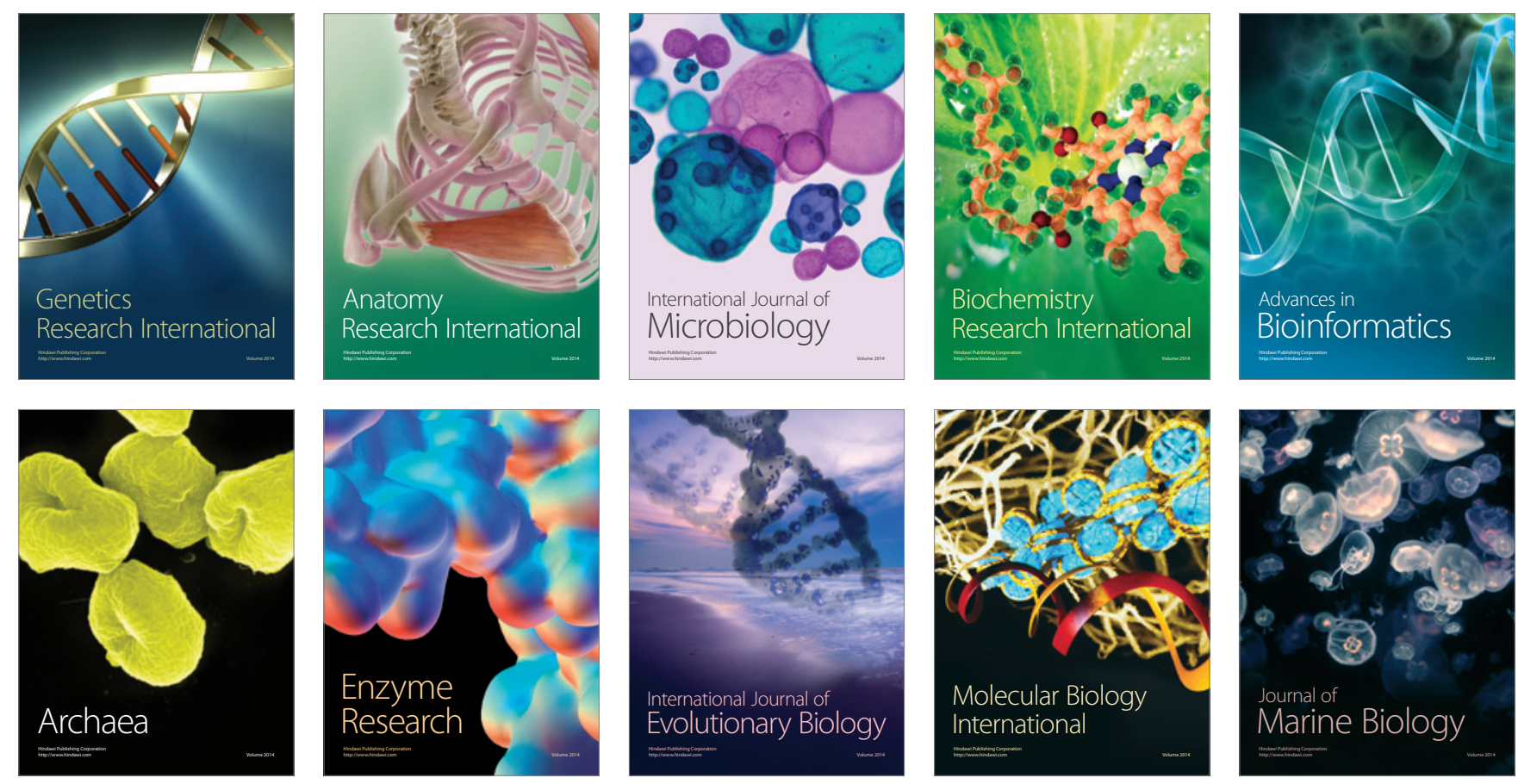